\title{
Infant head growth in male siblings of children with and without autism spectrum disorders
}

\author{
John N. Constantino - Palak Majmudar • Alex Bottini • \\ Molly Arvin • Yamini Virkud • Paul Simons • \\ Edward L. Spitznagel
}

Received: 3 March 2009/Accepted: 13 October 2009/Published online: 21 November 2009

(C) Springer Science + Business Media, LLC 2009

\begin{abstract}
Previous research has indicated that children with autism exhibit accelerated head growth (HG) in infancy, although the timing of acceleration varies between studies. We examined infant HG trajectory as a candidate autism endophenotype by studying sibling pairs. We retrospectively obtained serial head orbitofrontal circumference measurements of: a) 48 sibling pairs in which one $(n=28)$ or both $(n=20)$ sibs were affected by an autism spectrum disorder (ASD); and b) 85 control male sibling pairs. Rate of HG of ASD subjects was slightly accelerated compared to controls, but the magnitude of difference was below the limit of reliability of standard measurement methods. Sibling intra class correlation for rate of $\mathrm{HG}$ was highly statistically significant; the magnitude was significantly stronger among autism-affected families $(\mathrm{ICC}=.63)$ than among controls $(\mathrm{ICC}=.26), p<.01$. Infant HG trajectory appears
\end{abstract}

\author{
J. N. Constantino \\ Departments of Psychiatry and Pediatrics, Washington University, \\ Saint Louis, MO, USA \\ P. Majmudar $\cdot$ A. Bottini $\cdot$ M. Arvin \\ Department of Psychiatry, Washington University, \\ Saint Louis, MO, USA \\ Y. Virkud • P. Simons \\ Department of Pediatrics, Washington University, \\ Saint Louis, MO, USA \\ E. L. Spitznagel \\ Department of Mathematics, Washington University, \\ Saint Louis, MO, USA \\ J. N. Constantino $(\bowtie)$ \\ Washington University School of Medicine, \\ 660 South Euclid Avenue, Campus Box 8134, Saint Louis, \\ MO 63110, USA \\ e-mail: constantino@wustl.edu
}

familial - possibly endophenotypic — but was not a reliable marker of autism risk among siblings of ASD probands in this sample.

Keywords Infancy - Head circumference - Brain growth Autism $\cdot$ Endophenotype $\cdot$ Pervasive developmental disorder

\section{Introduction}

Although the specific neural mechanisms that underlie autism spectrum disorders (ASD) are not yet known, it is likely that subtle neuroanatomical abnormalities precede the development of observable behavioral symptoms in infants with ASD, and a suggested candidate marker for those abnormalities is the trajectory of brain growth during the first 2 years of life. A number of published studies have provided evidence for time-limited acceleration in early head growth, but the studies have varied in methodology, sample size, and in the results, especially with respect to the precise timing of that acceleration. Given current evidence that there are disparate genetic pathways to the development of ASD (Geschwind 2008), and that our ability to control for these differences in research studies is severely limited, it is possible that sample heterogeneity has contributed to some of the inconsistency in the findings to date.

In this report, we briefly review what is known about early brain growth in ASD-affected infants, and present findings from a study exclusively involving sibling pairs: those concordantly affected by ASD, those discordant for ASD, and those concordantly unaffected by ASD. ASDs occur four times more commonly in boys than in girls and are heavily influenced by genetic factors: to our knowledge, only one prior study of infant head growth trajectory 
in ASD has employed a sibling or family design. In that study, Elder et al. (2008) investigated whether infant siblings $(n=77)$ of children with ASD who exhibited an atypical trajectory of head circumference (HC) growth were more likely than those without an atypical HC trajectory to develop autistic symptoms. Results showed that infants who had larger $\mathrm{HC}$ at 12 months, and whose $\mathrm{HC}$ growth rate decelerated more rapidly between 12 months and 24 months were more likely to exhibit autism symptoms than infants with more typical $\mathrm{HC}$ trajectories.

The results of prior research studies examining HC trajectory in children are summarized in Table 1, which also includes summary information for this study for comparison. Following a report by Lainhart et al. (1997), in which it was reported that among children with autism and macrocephaly, $80 \%$ had shown no sign of macrocephaly at birth, Courchesne et al. (2003) reported that $\mathrm{HCs}$ in 48 autistic subjects increased (on average) from the 25th percentile at birth to the 84th percentile (in reference to the FELS longitudinal study sample (Guo et al. 1988)) during the interval from birth to 14 months of age. Redcay and Courchesne (2005) performed a metaanalysis of 15 studies of head circumference/brain volume in autism that had been conducted prior to 2005 and concluded that there was evidence for both pathological brain growth and arrest of growth during the first years of life. Fukumoto et al. (2008) subsequently observed that abnormalities in $\mathrm{HC}$ trajectory in autism began as early as the first month of life.

Hazlett et al. (2005) conducted one of the largest studies to date, and one that employed both head measurements and structural brain MRI. Their study suggested that head growth acceleration in autism might begin somewhat later. They compared 18-35 month old children diagnosed with autism $(n=113)$ to a normal control group using measurements of a) brain volume (structural MRI), b) retrospectively-obtained head circumference measurements from the time of birth, or c) both. The analyses from both measurement methods supported an increase in the rate of head growth in children with autism beginning at around 12 months of age and persisting through the second year of life. Of note is that subsequent studies involving this sample suggested that common allelic variations in the serotonin transporter gene (Wassink et al. 2007) and the monoamine oxidase A gene (Davis et al. 2008) were associated with cortical enlargement in the children with autism but not necessarily in control subjects. Separate studies have implicated a role for the HOXA1 A218G polymorphism on increased head circumference in both children with autism (Conciatori et al. 2004) and normal controls(Muscarella et al. 2007).
Some studies have suggested that an increase in the rate of head growth could be the result of an overall increase in general body growth of autistic children (Fukumoto et al. 2008; Dawson et al. 2007; Torrey et al. 2004; van Daalen et al. 2007). Dawson et al. (2007) and Fukumoto et al. (2008) reported, however, that even after correcting for measurements in the child's body length and height, $\mathrm{HC}$ trajectories were still accelerated in children with autism.

The current study builds on the existing scientific literature on head growth in autism in three specific ways. First, it examined sibling pairs, from 48 ASD-affected families and 85 non-ASD families ascertained in the same geographic region across completely overlapping birth years. This allowed estimation of sibling correlation for head growth in both ASD-affected and control sub samples, which is directly relevant to the question of whether head growth trajectory might constitute an autism endophenotype (see "Discussion"). In addition, the use of unaffected contemporaneous sibling pairs averts the problem of basing comparisons on norms generated in older or separatelyascertained birth cohorts. Second, the study incorporated quantitative trait measurements of autistic social impairment among children with ASD and their siblings, which allowed examination of the association between head growth and the severity of autistic symptomatology, not only in index ASD cases but in affected and unaffected siblings. Finally, the sample was comprised of relatively high-functioning ASD subjects, and therefore potentially less-affected by the confound of cognitive impairment that might separately relate to head growth abnormalities in studies involving lower-functioning autistic subjects.

The head growth data for this study consisted of serial orbitofrontal circumference measurements recorded by the subjects' pediatricians and acquired retrospectively from their medical records. Although serial measurements of orbitofrontal circumference are less precise than brain volumes derived from neuroimaging procedures, the measurement of $\mathrm{HC}$ represents (on a public health level) a risk variable that can be feasibly and reliably obtained for screening purposes in the general population. Previous research has strongly supported the validity of $\mathrm{HC}$ measurement as a proxy for brain volume in screening (for example) for hydrocephalus and other forms of macrocephaly. Hazlett et al. (2005) observed a coefficient of correlation between $\mathrm{HC}$ measurements and total brain volume of 0.88 in their sample of 18-35 month old infants with and without autism. Similarly, in a sample of 230 preterm infants, Cheong et al. (2008) reported a strong correlation $(r=0.68)$ between $\mathrm{HC}$ and brain volume. The reliability of $\mathrm{HC}$ measurements among the practitioners who recorded the data acquired for this study is specifically addressed in the "Methods" section of this report. 
Table 1 A summary of published studies comparing head growth in children with autism vs. controls ${ }^{\mathrm{a}}$

\begin{tabular}{|c|c|c|c|c|c|c|c|c|}
\hline Study & $\mathrm{n} \mathrm{ASD}{ }^{\mathrm{a}}$ & $\begin{array}{l}\text { Dev. } \\
\text { period of } \\
\text { measurement } \\
\text { (months) }\end{array}$ & $\begin{array}{l}\text { Mean IQ } \\
\text { of subjects }\end{array}$ & Control group & $\begin{array}{l}\text { Method of } \\
\text { measurement }\end{array}$ & $\begin{array}{l}\text { 1st year of } \\
\text { life principle } \\
\text { findings }\end{array}$ & $\begin{array}{l}\text { 12-36 month } \\
\text { significant } \\
\text { findings }\end{array}$ & $\begin{array}{l}\text { Analytic } \\
\text { method }^{\mathrm{b}}\end{array}$ \\
\hline $\begin{array}{l}\text { 1. Courchesne } \\
\text { et al. } 2003\end{array}$ & 48 & Birth-14 & 75 & $\begin{array}{l}\text { CDC Norms/FELS } \\
\text { longitudinal } \\
\text { sample study }\end{array}$ & $\begin{array}{l}\text { OFC } \\
\text { and MRI }\end{array}$ & $\begin{array}{l}\text { Birth-14 month } \\
\text { (acceleration) }\end{array}$ & & $\begin{array}{l}\text { Cross- } \\
\text { sectional }\end{array}$ \\
\hline $\begin{array}{l}\text { 2. Torrey } \\
\text { et al. } 2004\end{array}$ & 15 & Birth-14 & 56.8 & $\begin{array}{l}\text { NCPP (1959-1965 } \\
\text { birth cohorts) }\end{array}$ & OFC & $\begin{array}{l}\text { Difference at } \\
\text { birth } \\
\text { but no } \\
\text { difference } \\
\text { in growth } \\
\text { trajectory }\end{array}$ & $\begin{array}{l}\text { [no } \\
\quad \text { difference }]\end{array}$ & $\begin{array}{l}\text { Cross- } \\
\text { sectional, } \\
\text { growth } \\
\text { curve }\end{array}$ \\
\hline $\begin{array}{l}\text { 3. Hazlett } \\
\text { et al. } 2005\end{array}$ & 113 & Birth-36 & 54.1 & $\begin{array}{l}\text { Contemporaneous } \\
\text { controls with } \\
\text { TYP } \\
(n=178) \text { or DD } \\
(n=11)\end{array}$ & $\begin{array}{l}\text { OFC } \\
\text { and MRI }\end{array}$ & [no difference] & $\begin{array}{l}\text { 12-24 } \\
\quad \text { months } \\
\text { (acceleration) }\end{array}$ & $\begin{array}{l}\text { Cross- } \\
\text { sectional, } \\
\text { growth } \\
\text { curve } \\
\text { analysis }\end{array}$ \\
\hline $\begin{array}{l}\text { 4. Fukumoto } \\
\text { et al. } 2008\end{array}$ & 85 & Birth-12 & 75.5 & $\begin{array}{l}\text { JMHLW } 2000 \\
\text { infant physical } \\
\text { growth survey }\end{array}$ & OFC & $\begin{array}{l}\text { 1-12 month } \\
\text { (acceleration) }\end{array}$ & & $\begin{array}{l}\text { Cross- } \\
\text { sectional }\end{array}$ \\
\hline $\begin{array}{l}\text { 5. Elder } \\
\text { et al. } 2008 \\
\text { (Study of } 77 \\
\text { high- risk sibs) }\end{array}$ & $\begin{array}{l}\text { Not } \\
\text { Reported }\end{array}$ & Birth-24 & $\begin{array}{l}\text { Not } \\
\text { Reported }\end{array}$ & 2002 CDC Norms & OFC & $\begin{array}{l}\text { Birth-12 month } \\
\text { (acceleration) }\end{array}$ & $\begin{array}{l}\text { 12-24 } \\
\text { months } \\
\text { (deceleration) }\end{array}$ & $\begin{array}{l}\text { Cross- } \\
\text { sectional, } \\
\text { multilevel } \\
\text { modeling }\end{array}$ \\
\hline $\begin{array}{l}\text { 6. Dawson } \\
\text { et al. } 2007 \\
\text { (deceleration) }\end{array}$ & 28 & Birth-36 & $\begin{array}{l}61.5 \\
\text { (Mullen } \\
\text { Composite) }\end{array}$ & 2002 CDC Norms & OFC & $\begin{array}{l}\text { Birth-12 month } \\
\text { (acceleration) }\end{array}$ & $\begin{array}{l}\text { 12-36 } \\
\text { months } \\
\text { (relative } \\
\text { deceleration) }\end{array}$ & $\begin{array}{l}\text { Cross- } \\
\text { sectional, } \\
\text { growth } \\
\text { curve }\end{array}$ \\
\hline $\begin{array}{l}\text { 7. Webb } \\
\text { et al. } 2007\end{array}$ & 28 & Birth-36 & $\begin{array}{l}\text { Not } \\
\text { Reported }\end{array}$ & 2000 CDC Norms & OFC & $\begin{array}{l}\text { 7-10 month } \\
\text { (acceleration) }\end{array}$ & & $\begin{array}{l}\text { Cross- } \\
\text { sectional }\end{array}$ \\
\hline $\begin{array}{l}\text { 8. van Daalen } \\
\text { et al. } 2007\end{array}$ & 53 & Birth -64 & $\begin{array}{l}<70: 33 \\
70-85: 6 \\
>85: 14\end{array}$ & $\begin{array}{l}\text { 1996, } 1997 \\
\text { NOASR }\end{array}$ & OFC & [no difference] & [no difference] & $\begin{array}{l}\text { Cross- } \\
\text { sectional }\end{array}$ \\
\hline $\begin{array}{l}\text { 9. Constantino } \\
\text { et al. [Current } \\
\text { Study] }\end{array}$ & 48 & Birth-36 & 92 & $\begin{array}{l}\text { Unaffected } \\
\text { sibs and } \\
\text { contemporaneous } \\
\text { control sib pairs }\end{array}$ & OFC & $\begin{array}{l}\text { Birth-15 } \\
\text { month } \\
\text { (trend, } \\
\text { acceleration) }\end{array}$ & & $\begin{array}{l}\text { Cross- } \\
\text { sectional, } \\
\text { growth } \\
\text { curve }\end{array}$ \\
\hline
\end{tabular}

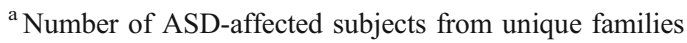

${ }^{\mathrm{b}} \mathrm{P}$-Values for principal differences between ASD subjects and controls

1. Comparison of 22 ASD infants vs. 31 controls with birth -14 month data indicated a significantly greater increase in $\mathrm{HC}, p<.001$

2. At 4 months, the $\mathrm{HC}$ of the ASD subjects was not significantly larger than the $\mathrm{HC}$ of the controls $(p=.07)$

3. The growth curves for subjects with autism vs. controls were significantly different; $p<.001$ for all three parameters comprising the curves

4. In the low functioning ASD boys, HC differed from the controls at 1 month $(p=.0008), 3$ months $(p=.025)$, and 6 months ( $p=.0001)$. The high functioning ASD boys differed from the controls at 6 months $(p=.02)$

5. Whole group cross-sectional differences between high risk siblings and CDC norms are significantly different at $6-12$ months, $p<.05$ at each time point; birth -12 month slopes are greater than CDC norms, $p<.001$. Subset with significant ASD symptoms (Early Developmental Interview, EDI or Modified Checklist for Autism in Toddlers, M-CHAT) vs. those without differed in 12-24 month HC slope (EDI, $p=.05)$, and exhibited a larger 12 month intercept (M-CHAT, $p=.02$ )

6. The orbitofrontal circumference (OFC) $z$-score for the ASD subjects at 12 months was significantly larger than the control group's $(p<.001)$. Although the rate of change of $\mathrm{HC}$ decreases from 12-36 months $(p=.001)$, the rate of change does not significantly differ from that of the norms $(p=.409)$

7. The mean OFC $z$-scores in the ASD group did not significantly differ from the controls from $0-7$ months and from 10-13 months, but they were significantly larger than the controls from 7-10 $(p<.001)$ and 13-36 $(p<.007)$ months

8. No significant difference between ASD subjects and controls were found

9. Growth curve trajectory for ASD subjects mildly accelerated in comparison controls for age range birth -15 months, $p=.07$. The magnitude of difference was on the order of $0.03 \mathrm{~cm} / \mathrm{month}$ 


\section{Methods}

Participants

\section{Clinical sample: sibling pairs in ASD-affected families}

Participants included a total of 48 sibling pairs, concordant $(N=20)$ and discordant $(N=28)$ for ASD, who are subjects in our ongoing 5-year longitudinal study of social development at the Washington University (WU) School of Medicine as previously described in Constantino et al. (2006). The WU sample consists of families recruited from the Child and Adolescent Psychiatry Service at WU and local advertisements in the greater St. Louis metropolitan area, who met the following inclusion criteria: one index case affected by an ASD and a full biological male sibling age 4-18 years. For the ASD group, the diagnosis of the index child (in families with more than one affected child, the most severely affected child in the family) was confirmed by the Autism Diagnostic Interview-Revised (ADIR), the Autism Diagnostic Observation Schedule (ADOS), and expert clinician diagnosis. For all index cases, the ADIR and ADOS were positive. Affected status of siblings was confirmed by the same measures, which were performed whenever there existed clinical suspicion of an ASD diagnosis and/or a parent-report SRS score of 65 (raw) or greater. Nineteen of the index cases carried a clinician diagnosis of autistic disorder and 29 were individuals with clinical diagnoses of PDD-NOS or Asperger syndrome. The average full-scale IQ of this sample was 92 (SD 24). Forty-three of the probands were male and all siblings were male. In cases where there were multiple siblings of a clinically-ascertained proband, the male sibling closest in age to the proband was selected for inclusion in the study. Children born prematurely were excluded from the study.

\section{Non-clinical sample: sibling pairs from non-ASD (control) families}

Eighty-five unaffected male sibling pairs were used as a source of contemporaneous controls. The controls were recruited from the primary care service of Forest Park Pediatrics which generally represents the ethnic and socioeconomic distribution of families in the St. Louis metropolitan area. Records for this service were reviewed for the availability of prospectively acquired HC measurements in the infants of families for whom at least two male children (full siblings) were cared for and followed by the practice from birth. Families were excluded from the study if any one of the male siblings from the candidate pair carried a primary or secondary diagnosis of autism, prematurity, any neurological disorder, or serious chronic disease beginning in infancy according to the electronic medical record data from the practice. For these families, de-identified HC growth charts were provided to our research team in male sibling sets. This data acquisition was reviewed and approved by the Washington University Human Studies Committee and granted a waiver of consent for the use of existing de-identified data.

The data from the growth curves was entered electronically for all measurements depicted on the charts that were made at ages birth, 1 month, 2 months, 4 months, 6 months, 9 months, 10 months, 12 months, 15 months, 18 months, 21 months, 24 months, 27 months, 30 months, and 36 months. Head circumference values were recorded from entries on growth charts to the nearest $0.1 \mathrm{~cm}$.

Measures

\section{Head circumference}

In our study, $\mathrm{HC}$ data was retrospectively ascertained from growth charts available in the children's pediatric records. Pediatricians used standardized tape measures to obtain HC data. All subjects had available measurements for at least two time points (most often at 6 months and at least one later date); most had multiple additional measurements performed. All available measurements over the period from birth to 36 months were incorporated into this study. A listing of the total number of measurements is provided in Table 2, listed as a function of subject group and age at the time of measurement.

The validity of orbitofrontal circumference (OFC) as a proxy or correlate of brain volume is described in the "Introduction". In this study OFC measurements were made and recorded by a variety of pediatricians, eight physicians participating in measurements of the control sample, and numerous physicians contributing measurements for the clinical sample. Therefore, an additional step in establishing validity of these measurements involved examination of the correlation between closely spaced measurements in individual subjects. For this we computed intra class coefficients of correlation between 4 month and 6 month measurements and between 12 month and 18 month measurements. The intervening period from 6 months to 12 months represents an inflection point in the normal trajectory of head growth, the interval over which the plot of time verses HC levels off from a vertical to a horizontal orientation. For 4-6 months $\mathrm{r}=0.91$, and for $12-18$ months $r=0.93$, indicating a very high degree of test-retest reliability for these measurements.

\section{Social responsiveness scale (clinical sample only)}

In addition to categorical designation of affected status, index ASD cases and siblings in the clinical sample were 
Table 2 Total number of head circumference measurements incorporated in the study, as a function of subject group and age at the time of measurement

\begin{tabular}{lcccc}
\hline Month & Index ASD subjects & Sibs of ASD subject & Control sib 1 & Control sib 2 \\
\hline Birth & 18 & 24 & 43 & 55 \\
1 & 24 & 24 & 52 & 47 \\
2 & 35 & 37 & 78 & 79 \\
4 & 34 & 36 & 77 & 78 \\
6 & 38 & 39 & 77 & 72 \\
9 & 32 & 24 & 32 & 40 \\
10 & 8 & 14 & 28 & 13 \\
12 & 33 & 32 & 57 & 68 \\
15 & 21 & 27 & 67 & 51 \\
18 & 15 & 11 & 60 & 38 \\
21 & 0 & 3 & 11 & 7 \\
24 & 19 & 16 & 43 & 38 \\
27 & 0 & 0 & 3 & 8 \\
30 & 0 & 1 & 1 & 4 \\
36 & 1 & 0 & 1 & 0 \\
\hline
\end{tabular}

assessed by their parents with respect to quantitative severity ratings of autistic social impairment using a 65item rating scale, the Social Responsiveness Scale (SRS). The validity and psychometric properties of the SRS have been described extensively in previous published reports, and are summarized in the SRS manual (Constantino and Gruber 2005). Raw scores of 80 and above are highly consistent with ASD in males. Mean SRS scores were 102 for autistic disorder probands with an SD of 25, 90 for PDD-NOS/Asperger Disorder probands with an SD of 21, 107 for autistic disorder-affected siblings with an SD of 39, 85 for PDD-NOS/Asperger-affected siblings with an SD of 27, and 32 for non-ASD siblings with an SD of 29.

\section{Data analysis}

Time-rated change was estimated using two separate methods. First, we conservatively derived monthly growth rates from the time-rated change between measurements at birth, 6 months, 12 months, and 18 months, because this encompassed the developmental period over which a substantial number of subjects had at least two contiguous data points, and for which some previous studies have indicated the most pronounced discrepancies between autistic subjects and controls. Comparison of means for each developmental interval, between children with autistic disorder, children with PDD-NOS/Asperger Disorder, unaffected siblings of ASD probands, and unaffected controls was performed using Analysis of Variance (ANOVA). Given that the only females in the study were five ASD probands, we first restricted this analysis to males only, and then repeated the analysis incorporating the female probands. In addition, Pearson's coefficient of correlation between head growth rates and autistic severity (measured by the Social Responsiveness Scale) was computed for the siblings in the ASD-affected families.

Next, in order to take advantage of all of the available longitudinal measurements, linear and non-linear (quadratic) components of change over time were estimated from all available measurements on each subject, and slope coefficients were derived (using the least squares regression method) for each growth trajectory using SAS statistical software. We used a method highly analogous to that used for characterizing growth trajectory in Hazlett et al. (2005) and Elder et al. (2008). In essence, the growth curves were defined by an intercept, a parameter for acceleration, and a parameter for deceleration. Specifically, longitudinal measurement data was fit to the equation $\mathrm{y}=\mathrm{b}_{0}+\mathrm{b}_{1}\left(\mathrm{e}^{\wedge}\left(\mathrm{b} 2{ }^{*}\right.\right.$ age $)$, where $\mathrm{y}=$ head circumference; $b_{0}=$ random effect; $b_{1}=$ acceleration; and $\mathrm{b}_{2}=$ deceleration. The coefficients were then compared between ASD-affected subjects and unrelated controls (selecting at random one sib per family) using logistic regression methods, separately employing NLMIXED (in which growth trajectories are incorporated at the level of each individual subject) and NLIN in which all growth trajectories for a group are averaged to a single trajectory for group comparison. Finally, an omnibus test of significance was computed as an indicator of overall difference in growth trajectory across $b_{0}, b_{1}$, and $b_{2}$.

\section{Results}

Average rate of head growth over specific intervals (within the range from birth to 18 months) - for which male subjects had recorded measurement at the begin- 
ning and end-are presented for Autistic Disorder subjects, PDD-NOS/Asperger's subjects, unaffected siblings of ASD probands, and control sibling pairs in Table 3. As shown in the table, the differences between the average rates of head growth between the four groupings of subjects are subtle but generally in the predicted direction except that the rates for unaffected sibs of ASD probands were higher than for PDD/Asperger probands for the 6-12 month and 12-18 month intervals. With the exception of the interval from birth to 6 months $(F=2.78, \mathrm{~d} f 3,121, p=.04)$, the overall between-group differences did not quite reach statistical significance (see Table 3). The results were not significantly changed when incorporating into the analysis the five female ASD probands. As would be predicted from the mean rates of change for affected and unaffected siblings of ASD probands, there was no significant correlation between head growth rate and autistic severity as measured by the SRS in the sibling groups nor was there a significant correlation among probands.

Sibling intra class correlation for the average rate of head growth (from age 6-12 months, the developmental period for which the greatest number of subjects had complete data) in families affected by ASD was substantial, irrespective of whether the sibling of an index case was affected or unaffected, and highly statistically significant: $I C C=.63$. Similarly the correlation between male siblings in the control families was positive and statistically significant but the magnitude was not as great as that observed in the autism families: $I C C=.26$. This difference was statistically significant $(p=.01)$ and raises the possibility that even in the absence of clinically-appreciable mean differences in head growth between ASD subjects and controls, genetic factors associated with autism might operate to accentuate sibling correlations for head growth trajectory.

Although group differences in the defining parameters for the respective growth curves between ASD subjects ( $N=48$ probands) and unrelated controls $(N=85$, 1 per family selected at random) were in the expected direction-as illustrated in the depiction of averaged growth trajectories generated by NLIN in Fig. 1-they failed to reach statistical significance in either of the regression paradigms employed (NLIN, NLMIXED). In essence, head size in children with ASD began slightly lower than that of control subjects $(Z=-1.790 ; p=.07)$, proceeded at a mildly accelerated growth rate through the age of 15 months $(Z=1.795 ; p=.07)$ at which time the curves crossed and head growth in ASD subjects decelerated to a lesser extent than in the control group $(Z=-1.32$; $p=.18$ ), as depicted in Fig. 1. An omnibus test of significance of overall difference in growth trajectories just reached statistical significance $(p=.04)$.

\section{Discussion}

In this quasi-longitudinal study involving retrospectivelyacquired serial measurements of infant head growth in children with autism spectrum disorders (ASD), their male siblings, and unaffected male sibling pairs, head growth trajectories did not predict which male siblings of index autism cases went on to develop ASD, nor did they predict severity among those affected with clinical-level or subclinical symptomatology. We observed a slight relative acceleration in head growth trajectory in ASD subjects compared to controls, but the difference would not be feasibly measurable using standard clinical methods (i.e. tape measurement of orbitofrontal circumference), since it was on the order of millimeters. A striking finding of the study was the degree of familiality of head growth trajectories, parameterized in this study by sib correlation, which was significant for both autism families (irrespective of whether the siblings were concordant or discordant for ASD) and control families. The sib correlations were

Table 3 Comparison of mean head growth, in $\mathrm{cm}$./month (SD) for specified intervals, between male subjects with Autistic Disorder, PDDNOS/Asperger Disorder, unaffected siblings of ASD probands, and unrelated controls. Analysis (one-way ANOVA) includes only those

subjects with actual measurements at the beginning and end of each interval (i.e. not extrapolated from growth curves defined by measurements at other time points)

\begin{tabular}{llll}
\hline & Birth-6months & 6-12months & 12-18months \\
\hline Autistic disorder & $1.68(.17)$ & $.51(.13)$ & $.28(.13)$ \\
PDD-NOS/Asperger disorder & $1.63(.28)$ & $.53(.13)$ & $.20(.09)$ \\
Unaffected sibs of ASD probands & $1.55(.27)$ & $.56(.13)$ & $.31(.06)$ \\
Control siblings & $1.51(.18)$ & $.49(.11)$ & $.24(.08)$ \\
F & 2.78 & 2.44 & 2.55 \\
df & 3,121 & 3,172 & 3,86 \\
$\mathrm{p}$ & .04 & .07 & .06 \\
$2000 \mathrm{CDC}$ norms & 1.26 & 0.41 & 0.23 \\
\hline
\end{tabular}




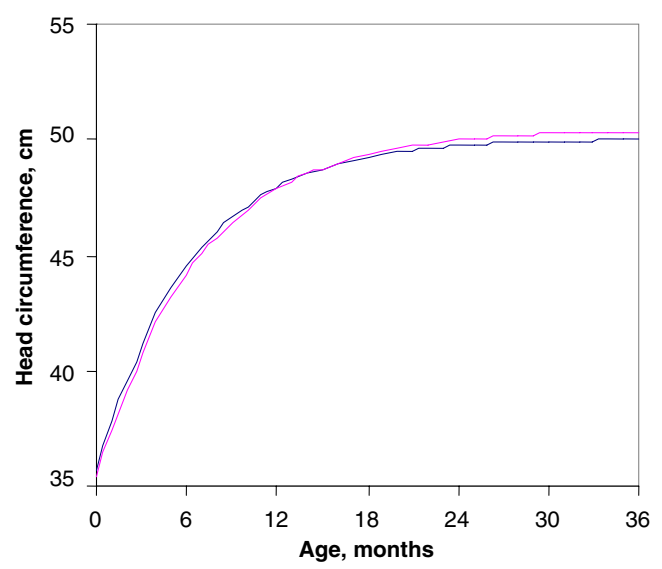

Fig. 1 Average head circumference, computed in Proc NLIN as a function of age in subjects with ASD (lighter curve) versus controls (darker curve)

significantly stronger in the ASD-affected families, suggesting that it is possible that within this group, there are inherited factors which might incur greater uniformity of head growth trajectory among siblings. If these inherited factors are related to those that cause autism, head growth trajectory may constitute a candidate autism endophenotype, i.e. an inherited substrate for autism susceptibility which, alone, is not sufficient to produce an autistic syndrome. We suggest this cautiously, since our results showed a marginal difference in head growth trajectory between children with autism and contemporaneous controls. It is noteworthy that in this study the contemporaneous controls themselves, ascertained from a general pediatric clinic, exhibited rates of early head growth that exceeded CDC norms published in 2000. In future research it would be important to track whether similar studies in typical populations provide evidence for sustained trends in rate of head growth in children.

We note that other recent studies have identified familial aggregation of neuropsychological correlates of autism that do not necessarily predict clinical-level autistic impairment of relatives (Dawson et al. 2007; Dalton et al. 2007; Virkud et al. 2008). The elucidation of endophenotypes is potentially important since endophenotypes constitute phenotypic markers with which to trace specific components of susceptibility to the development of an inherited condition. Thus, although accelerated head growth might reflect a parameter of risk for autism, these data suggest that such a factor would need to interact with another factor (or factors) to contribute susceptibility to the autistic phenotype.

The design of this study obviated some of the limitations that have potentially influenced contrasting results in previously-reported research on this topic. The use of a contemporaneous control sample helped to minimize differences that might have been suggested if the growth trajectories of our ASD subjects were compared to historical (previously published) norms, however this particular set of control subjects may not necessarily represent the general population. We employed both cross-sectional comparisons and growth curve modeling in the analysis of data, and the results from both approaches were highly convergent. Given the known heritability of autistic syndromes, we were particularly interested in examining head growth and its relationship to autistic impairment within a sibling design, and this study was the first to implement such a design for both the ASD and control groups. In addition, and with the exception of five female index ASD cases, the sample was comprised entirely of males. Sibling recurrence in autism is three to four times higher in males than in females, so the exclusive enrollment of male siblings enhanced power to explore relationships between head growth trajectory and affected status in siblings.

Finally, and possibly an important cause of differences between these results and those of other published studies, it is important to note that our sample of ASD-affected children was relatively high-functioning (as operationalized by higher measured average IQ); this served to minimize possible effects of co-morbid mental retardation on head growth trajectories within this ASD sample. We note that Courchesne et al. (2003) observed that acceleration in head growth trajectory appreciable among their autistic subjects was less pronounced in patients with PDD-NOS. This discrepancy as a function of "severity of diagnosis" is possibly congruent with our findings of minimal abnormality in a generally higher-IQ ASD sample (encompassing both autistic disorder and Asperger Disorder/PDD-NOS). It is possible that cognitive impairment, specific causal mechanisms (e.g. among the many genetic pathways to autistic syndromes), or other parameters predicting functional severity may exert independent effects on head growth trajectory. Chiu et al (2007) for example, compared 22 boys with Fragile X Syndrome and Autistic Disorder to 22 boys with Fragile X Syndrome alone and observed different trajectories of growth from 12-60 months for the two groups: neither group differed from norms during the first year of life, and Fragile X only subjects exhibited greater head circumference than Fragile $\mathrm{X}$ plus autism subjects at 60 months. Williams et al. (2008) have recently reviewed and described the wide diversity of genetic conditions that result in macrocephaly in childhood. It is not yet known how infant head growth trajectories map to variations in head circumference later in life; however, we note that a large scale study of head size, measured crosssectionally at a single time point in 3- to 47-year-old individuals with autism and their first-degree relatives (Lainhart et al. 2006) demonstrated: a) no significant mean difference between affected and unaffected siblings of ASD probands; and b) substantial correlations in head size 
between affected individuals and their unaffected parents, yielding heritability estimates on the order of 0.50 .

Limitations of this study included sample size, the exclusive use of retrospectively-acquired head circumference measurements (rather than neuroimaging data), and missing data points in the medical records from which the measurements were retrieved. The latter was abrogated by the growth curve modeling methods used, but the primary limitationsample size - remains an important consideration, especially given the relatively narrow margin of difference observed between ASD and control subjects in our sample. There are currently efforts under way to pool prospective data on the head growth of infant siblings of children with autism across multiple study sites (for example, the NICHD BabySibs Consortium). We eagerly await the results of these efforts and hope that the sibling data from our control sample will be particularly useful for the interpretation of those results. In the mean time, the data from the relatively modest number of ASD-affected children in this study suggest that the magnitude of difference in the growth trajectory of affected versus unaffected infants may be very difficult to ascertain manually in clinical settings. At this point, unless head growth trajectories of infants are grossly abnormal (i.e. reaching clinical parameters for microcephaly or macrocephaly) they should be interpreted cautiously in predicting affectation status among later-born siblings of children with autism.

Acknowledgements This research was supported by a grant to Dr. Constantino from the National Institute of Child Health and Human Development (HD42541). The authors wish to thank the families participating in this study for their dedication to autism research and their efforts on this project.

\section{References}

Cheong JL, Hunt RW, Anderson PJ, et al. Head growth in preterm infants: correlation with magnetic resonance imaging and neurodevelopmental outcome. Pediatrics. 2008;121(6):e1534-40.

Chiu S, Wegelin JA, Blank J, et al. Early acceleration of head circumference in children with fragile $\mathrm{x}$ syndrome and autism. J Dev Behav Pediatr. 2007;28(1):31-5.

Conciatori M, Stodgell CJ, Hyman SL, et al. Association between the HOXA1 A218G polymorphism and increased head circumference in patients with autism. Biol Psychiatry. 2004;55 (4):413-9.

Constantino JN, Gruber CP. The social responsiveness scale (SRS) manual. Los Angeles: Western Psychological Services; 2005.

Constantino JN, Lajonchere C, Lutz M, et al. Autistic social impairment in the siblings of children with pervasive developmental disorders. Am J Psychiatry. 2006;163(2):294-6.
Courchesne E, Carper R, Akshoomoff N. Evidence of brain overgrowth in the first year of life in autism. Jama. 2003;290 (3):337-44.

Dalton KM, Nacewicz BM, Alexander AL, Davidson RJ. Gazefixation, brain activation, and amygdala volume in unaffected siblings of individuals with autism. Biol Psychiatry. 2007;61 (4):512-20.

Davis LK, Hazlett HC, Librant AL, et al. Cortical enlargement in autism is associated with a functional VNTR in the monoamine oxidase A gene. Am J Med Genet B Neuropsychiatr Genet. 2008;147B(7):1145-51.

Dawson G, Munson J, Webb SJ, Nalty T, Abbott R, Toth K. Rate of head growth decelerates and symptoms worsen in the second year of life in autism. Biol Psychiatry. 2007;61(4):458-64.

Elder LM, Dawson G, Toth K, Fein D, Munson J. Head circumference as an early predictor of autism symptoms in younger siblings of children with autism spectrum disorder. J Autism Dev Disord. 2008;38(6):1104-11.

Fukumoto A, Hashimoto T, Ito H, et al. Growth of head circumference in autistic infants during the first year of life. J Autism Dev Disord. 2008;38(3):411-8.

Geschwind DH. Autism: many genes, common pathways? Cell. 2008;135(3):391-5.

Guo S, Roche AF, Moore WM. Reference data for head circumference and 1-month increments from 1 to 12 months of age. J Pediatr. 1988;113(3):490-4.

Hazlett HC, Poe M, Gerig G, et al. Magnetic resonance imaging and head circumference study of brain size in autism: birth through age 2 years. Arch Gen Psychiatry. 2005;62(12):1366-76.

Lainhart JE, Piven J, Wzorek M, et al. Macrocephaly in children and adults with autism. J Am Acad Child Adolesc Psychiatry. 1997;36(2):282-90.

Lainhart JE, Bigler ED, Bocian M, et al. Head circumference and height in autism: a study by the Collaborative Program of Excellence in Autism. Am J Med Genet A. 2006;140(21):2257-74.

Muscarella LA, Guarnieri V, Sacco R, et al. HOXA1 gene variants influence head growth rates in humans. Am J Med Genet B Neuropsychiatr Genet. 2007;144B(3):388-90.

Redcay E, Courchesne E. When is the brain enlarged in autism? A meta-analysis of all brain size reports. Biol Psychiatry. 2005;58 (1): $1-9$.

Torrey EF, Dhavale D, Lawlor JP, Yolken RH. Autism and head circumference in the first year of life. Biol Psychiatry. 2004;56 (11):892-4.

van Daalen E, Swinkels SH, Dietz C, van Engeland H, Buitelaar JK. Body length and head growth in the first year of life in autism. Pediatr Neurol. 2007;37(5):324-30.

Virkud YV, Todd RD, Abbacchi AM, Zhang Y, Constantino JN. Familial aggregation of quantitative autistic traits in multiplex versus simplex autism. Am J Med Genet B Neuropsychiatr Genet. 2008

Wassink TH, Hazlett HC, Epping EA, et al. Cerebral cortical gray matter overgrowth and functional variation of the serotonin transporter gene in autism. Arch Gen Psychiatry. 2007;64(6):709-17.

Webb SJ, Nalty T, Munson J, Brock C, Abbott R, Dawson G. Rate of head circumference growth as a function of autism diagnosis and history of autistic regression. J Child Neurol. 2007;22(10):1182-90.

Williams CA, Dagli A, Battaglia A. Genetic disorders associated with macrocephaly. Am J Med Genet A. 2008;146A(15):2023-37. 